\title{
Diabetes and hypertension increase the placental and transcellular permeation of the lipophilic drug diazepam in pregnant women
}

\author{
Mladena Lalic-Popovic ${ }^{*}$, Jovana Paunkovic ${ }^{2}$, Zorica Grujic ${ }^{3}$, Svetlana Golocorbin-Kon ${ }^{1,4}$, Hani Al-Salami 5,6
} and Momir Mikov ${ }^{4,5,7}$

\begin{abstract}
Background: Previous studies carried out in our laboratories have demonstrated impaired drug permeation in diabetic animals. In this study the permeation of diazepam (after a single dose of $5 \mathrm{mg} / \mathrm{day}$, administered intramuscularly) will be investigated in diabetic and hypertensive pregnant women.

Methods: A total 75 pregnant women were divided into three groups: group 1 (healthy control, $n=31$ ), group 2 (diabetic, $n=14$ ) and group 3 (hypertensive, $n=30$ ). Two sets of diazepam plasma concentrations were collected and measured (after the administration of the same dose of diazepam), before, during and after delivery. The first set of blood samples was taken from the mother (maternal venous plasma). The second set of samples was taken from the fetus (fetal umbilical venous and arterial plasma). In order to assess the effect of diabetes and hypertension on diazepam placental-permeation, the ratios of fetal to maternal blood concentrations were determined. Differences were considered statistically significant if $p \leq 0.05$.

Results: The diabetes and hypertension groups have 2-fold increase in the fetal umbilical-venous concentrations, compared to the maternal venous concentrations. Feto: maternal plasma-concentrations ratios were higher in diabetes $(2.01 \pm 1.10)$ and hypertension $(2.26 \pm 1.23)$ groups compared with control $(1.30 \pm 0.48)$ while, there was no difference in ratios between the diabetes and hypertension groups. Umbilical-cord arterial: venous ratios (within each group) were similar among all groups (control: $0.97 \pm 0.32$; hypertension: $1.08 \pm 0.60$ and diabetes: $1.02 \pm 0.77$ ).

Conclusions: On line with our previous findings which demonstrate disturbed transcellular trafficking of lipophilic drugs in diabetes, this study shows significant increase in diazepam placental-permeation in diabetic and hypertensive pregnant women suggesting poor transcellular control of drug permeation and flux, and bigger exposure of the fetus to drug-placental transport.
\end{abstract}

Keywords: Drug placental-permeation, Diazepam, Diabetes, Hypertension

\section{Background}

The development and progression of diabetes have been associated with disturbed drug absorption due to dysfunctional protein expression and functionality, impaired transcellular transport and intercellular trafficking as well as altered gut physiology [1].

Due to the widespread rise in early detection of highrisk pregnant women in need of cesareans, its use is

\footnotetext{
* Correspondence: mladena.l@hotmail.com

${ }^{1}$ Department of Pharmacy, Faculty of Medicine, University of Novi Sad, Novi Sad, Serbia

Full list of author information is available at the end of the article
}

rapidly increasing worldwide. High-risk pregnant women include those with uncontrolled diabetes, hypertension and pre-eclampsia [2-4]. Diazepam is used in the treatment of maternal eclampsia and as a premedication in cesarean section deliveries. It is highly lipophilic drug with linear pharmacokinetics [5]. Diazepam readily crosses the blood-brain barrier and the placenta by passive diffusion. It is also excreted into breast milk and recent studies show that diazepam reaches equilibrium in the feto-maternal systemic circulation 10-15 minutes after intravenous administration [6].

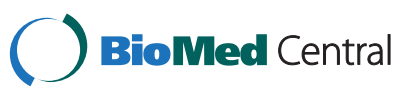


Passive diffusion rate depends on physicochemical properties of the drug; protein binding and state of placental barrier (i.e. blood flow). Some diseases such as diabetes and hypertension have been associated to impaired placental composition and functions. Moreover, pregnancy in diabetic and hypertensive women is directly linked to increased fetal morbidity and mortality [7-9]. These may be in a part related to changes in placental transport of maternal nutrients to the fetus and consequent abnormal placental development [10-13]. Placental dysfunction may result from a reduced placental blood flow and placental infarctions [14,15].

Despite the fact that diazepam has been used for many years in pregnancy, its direct placental permeation, in diabetic and hypertensive pregnant women, remains poorly understood. Thus the purpose of this study is to investigate the influences of diabetes and hypertension on the transplacental permeation of diazepam, after intramuscular injection to pregnant women.

\section{Methods}

\section{Subjects}

Pregnant women were recruited from the Gynecology and Obstetric clinic of Vojvodina (Serbia). Pregnant women scheduled for cesarean section, those who were diagnosed with gestational or arterial hypertension [16] as well as those who were diagnosed gestational diabetes [17] were included in this study. A total of 75 pregnant women were divided into three groups: healthy control group ( $\mathrm{n}=31)$, diabetes group $(\mathrm{n}=14)$ and hypertension group $(\mathrm{n}=30)$. Gestational or arterial hypertension was diagnosed according to The Good Clinical Practice National Guidelines on Diagnostic and Treatment of Arterial Hypertension [16]. Gestational diabetes mellitus was diagnosed according to The Good Clinical Practice National Guidelines on Diabetes Mellitus [17]. Three women in diabetes group were receiving insulin and the rest were on diabetes diet. The women in hypertension group were on methyldopa regular dosing. Prior to enrolment into the study, medical history was taken and a physical examination was performed. Only women with normal renal and liver function were included. Diazepam was applied by intramuscular injection (i.m.; $5 \mathrm{mg} /$ day) into gluteal muscle of mothers. Maternal demographic data (i.e. age, height and weight) and neonatal birth weight, length and $1^{\text {st }}$ and $5^{\text {th }}$ minute Apgar scores were taken. The study protocol was approved by Ethic Committee of the Gynecology and Obstetistric clinic in Vojvodina ( $\left.\mathrm{N}^{\circ} 00-08 / 9\right)$ and informed consents were obtained from each participant before inclusion in the study. Before the cesarean section, a spinal anaesthesia with $0.5 \%$ bupivacaine hydrochloride or a general anaesthesia with propofol, succinylcholine and fentanyl were applied as a part of the clinic common procedures. Spinal anaestheisa was applied to 11 women in the control group, 2 women in the diabetes group and 3 women in the hypertension group. General anaesthesia was applied to 20 women in the control group, 27 women in the hypertension group and 12 women in the diabetes group.

\section{Sample collection}

Maternal peripheral venous blood samples $(2 \mathrm{~mL})$ were collected from the arm using an indwelling cannula. Three samples were collected from all mothers. First sample was taken after application of diazepam and before cesarean section (time $t_{1}$ ). Second sample of maternal blood was taken at the same time with clamping of the infant's umbilical cord (time $t_{2}$ ). Third sample was taken after cesarean section (time $t_{3}$ ). Times $t_{1}, t_{2}$ and $t_{3}$ are presented in Table 1. Neonatal umbilical cord venous and arterial samples were obtained from a section of umbilical cords, cross clamped at delivery. Blood samples were collected in a vacutainer containing EDTA.

\section{Sample extraction}

Plasma was transferred to plastic tubes after centrifugation and frozen at $-20^{\circ} \mathrm{C}$ prior to analysis. Diazepam from plasma samples was extracted by liquid-liquid extraction. To $0.5 \mathrm{~mL}$ of plasma sample was added $0.5 \mathrm{~mL}$ of mixture of $5 \mathrm{M}$ sodium hydroxide and $3 \mathrm{M}$ sodium chloride. Mixture was vortexed for 30 seconds and then added $2.5 \mathrm{~mL}$

Table 1 Summary of a) feto: maternal diazepam plasma concentration ratios $\left(C_{v} / C_{m}\right)$; b) umbilical cord arterial: venous diazepam plasma concentration ratios $\left(C_{a} / C_{v}\right)$, and $\left.c\right)$ times of sample collection $t_{1}, t_{2}$ and $t_{3}$ (min) (mean $\pm s t a n d a r d$ deviation (min-max))

\begin{tabular}{cccc}
\hline Number of women $[\mathbf{N}=\mathbf{7 5}]$ & Control group $[\mathbf{n}=\mathbf{3 1}]$ & Hypertension group [ $=\mathbf{3 0}]$ & Diabetes group [ $=\mathbf{1 4 ]}$ \\
\hline $\mathbf{C}_{\mathbf{v}} / \mathbf{C}_{\mathbf{m}}$ & $1.30 \pm 0.48(0.59-2.27)$ & $2.26 \pm 1.23(0.25-4.21) \#$ & $2.01 \pm 1.10(0.42-3.77) \# \#$ \\
$\mathbf{C}_{\mathbf{a}} / \mathbf{C}_{\mathbf{v}}$ & $0.97 \pm 0.32(0.1-1.60)$ & $1.08 \pm 0.60(0.33-2.50)$ & $1.02 \pm 0.77(0.17-2.97)$ \\
$\mathbf{t}_{\mathbf{1}}(\mathbf{m i n})$ & $25.9 \pm 21.51(5-118)$ & $28.70 \pm 18.18(10-93)$ & $20.31 \pm 11.84(7-42)$ \\
$\mathbf{t}_{\mathbf{2}}(\mathbf{m i n})$ & $60.23 \pm 31.87(18-144)$ & $64.37 \pm 22.69(25-114)$ & $45.38 \pm 30.25(18-138)$ \\
$\mathbf{t}_{\mathbf{3}}(\mathbf{m i n})$ & $132.39 \pm 42.07(67-230)$ & $130.40 \pm 39.90(76-278)$ & $122.38 \pm 22.61(92-172)$ \\
\hline
\end{tabular}


of chloroform for extraction and after vortexing 90 seconds sample was centrifuged 10 minutes at $3500 \mathrm{rpm}(2100$ $\mathrm{rcf}), 1.5 \mathrm{~mL}$ of the lower layer was transferred to glass tubes, evaporated at $60^{\circ} \mathrm{C}$ and before injection to HPLC system reconstituted with $100 \mu \mathrm{l}$ of mobile phase. A $20 \mu \mathrm{l}$ of sample was injected into HPLC system.

\section{Sample analysis}

Diazepam concentrations in plasma were measured by modified HPLC method previously described [18]. HPLC system (Dionex) consisted of Agilent column $(5 \mu \mathrm{m}$, $100 \mathrm{~mm} \times 2.1 \mathrm{~mm}$ ) with guard column (Agilent; $5 \mu \mathrm{m}$, $20 \mathrm{~mm} \times 2.1 \mathrm{~mm}$ ). Mobile phase was consisted of $50 \mathrm{mM}$ potassium dihydrogen phosphate buffer $(\mathrm{pH} 3)$ and acetonitril in ration $65: 35(\mathrm{v} / \mathrm{v})$, at flow rate $0.4 \mathrm{~mL} / \mathrm{min}$. Retention time for diazepam was 7.5 minutes. UV detection was set at $230 \mathrm{~nm}$. Analyses were done at room temperature $\left(25^{\circ} \mathrm{C}\right)$. The limit of detection (LOD) was $0.005 \mu \mathrm{g} / \mathrm{mL}$ and limit of quantification (LOQ) $0.01 \mu \mathrm{g} /$ $\mathrm{mL}$ with recovery of $94.33 \pm 2.12$. The calibration curve was linear in the concentration range of $0.01-10 \mu \mathrm{g} / \mathrm{mL}$.

\section{Statistical analysis}

All data were measured as mean \pm standard deviation (SD). Data were analyzed using one way analysis of variance (ANOVA) and the means were compared using Tukey`s test $(\mathrm{P} \leq 0.05)$ via SPSS 17.0 (Systat Software Inc., San Jose, CA). Differences were considered significant if $\mathrm{p} \leq 0.05$. Areas under the curve (AUC) were calculated by trapezoidal method using WinNonLin (version 4.1; SCI software, Pharsight Corp., Gary NC, USA). Feto: maternal concentration ratios $\left(c_{v} / c_{m}\right)$ were calculated by dividing diazepam concentrations in neonatal umbilical venous blood by concentrations in maternal venous blood. Also umbilical cord arterials to umbilical cord venous concentration ratios $\left(\mathrm{c}_{\mathrm{a}} / \mathrm{c}_{\mathrm{v}}\right)$ were determined as a measure of diazepam uptake, distribution and/or metabolism in neonates.

\section{Results}

\section{Demographic characteristics}

There were total 75 women included in the study scheduled for cesarean section. All women went through normal pregnancy and gave birth to healthy single newborns. The age of included women was between 20 and 42 years. There were no statistically significant differences neither in height, weight nor body surface area $\left(\mathrm{BSA} ; \mathrm{m}^{2}\right)$ of the women between three investigated groups (Table 2). Also, doses of diazepam normalized per body mass $(\mathrm{mg} / \mathrm{kg})$ and BSA $\left(\mathrm{mg} / \mathrm{m}^{2}\right)$ were not statistically different between groups (Table 2). However, systolic and diastolic pressures were statistically significantly higher in hypertension group compared to diabetes and control group as expected. All women in hypertension group were receiving methyldopa $(250 \mathrm{mg})$ and in diabetes group 3 women were receiving insulin and the rest were on diabetes diet.

All neonates were similar in length, weight and BSA (Table 3). Also Apgar scores for all the newborn babies, measured in $1^{\text {st }}$ and $5^{\text {th }}$ minute after birth, were mostly normal. In control group there were 2 neonates with $1^{\text {st }}$ minute Apgar score 6 and one neonate with $1^{\text {st }}$ minute Apgar score 5. Also, one newborn infant in the group of women with diabetes had $1^{\text {st }}$ minute Apgar score 6 and two neonates in group of women with hypertension had $1^{\text {st }}$ minute Apgar score 5 . All neonates had $5^{\text {th }}$ minute Apgar score 7 or above. Statistically significant differences were observed in gestational age of children, where children in hypertension and diabetes group of women were delivered earlier. Transfer of diazepam starts from $6^{\text {th }}$ week of gestation and further its transfer is not dependant on gestational age thus the differences

Table 2 Summary of demographic characteristics of mothers and dosage details (mean \pm standard deviation (min-max)

\begin{tabular}{cccc}
\hline Number of women $[\mathbf{N}=\mathbf{7 5}]$ & Control group $[\mathbf{n = 3 1 ]}$ & Hypertension group [n=30] & $\begin{array}{c}\text { Diabetes group [n=14] } \\
\mathbf{N}=\mathbf{3 0}=14\end{array}$ \\
\hline Age $[$ years] & $31.03 \pm 4.13(23-40)$ & $33.87 \pm 5.72(20-42)$ & $32.14 \pm 5.79(24-41)$ \\
Height $[\mathrm{m}]$ & $1.65 \pm 0.078(1.52-1.81)$ & $1.66 \pm 0.059(1.51-1.80)$ & $1.65 \pm 0.065(1.53-1.78)$ \\
Weight $[\mathrm{kg}]$ & $79.97 \pm 14.09(60-136)$ & $95.71 \pm 22.69(51-142)$ & $87.00 \pm 21.51(60-127)$ \\
BSA $\left[\mathrm{m}^{2}\right]^{*}$ & $1.87 \pm 0.23(1.09-2.59)$ & $2.087 \pm 0.28(1.48-2.62)$ & $1.97 \pm 0.27(1.61-2.45)$ \\
BMI $\left[\mathrm{kg} / \mathrm{m}^{2}\right]^{* *}$ & $29.69 \pm 6.65(18.87-41.51)$ & $32.66 \pm 7.74(19.2-43.2)$ & $30.77 \pm 7.47(18.37-42.47)$ \\
Systolic pressure $(\mathrm{mmHg})$ & $111.3 \pm 11.9(90-130)$ & $150.0 \pm 14.3(130-180) \#$ & $120.0 \pm 16.4(90-150) \Delta$ \\
Diastolic pressure $(\mathrm{mmHg})$ & $70.6 \pm 8.5(60-80)$ & $96.7 \pm 8.8(80-120) \#$ & $73.6 \pm 9.3(60-90) \Delta$ \\
Dose $(\mathrm{mg} / \mathrm{kg})$ & $0.063 \pm 0.0084(0.04-0.08)$ & $0.057 \pm 0.014(0.04-0.10)$ & $0.061 \pm 0.014(0.04-0.08)$ \\
Dose $\left(\mathrm{mg} / \mathrm{m}^{2}\right)$ & $2.66 \pm 0.23(1.93-3.12)$ & $2.45 \pm 0.35(1.91-3.38)$ & $2.58 \pm 0.36(2.04-3.11)$ \\
\hline
\end{tabular}

*Boyd 's equation $\mathrm{BSA}=0.000327 *$ weight $(\mathrm{g})(0.7285-0.0188 \log 10$ weight $(\mathrm{g})){ }^{*}$ height $(\mathrm{cm})$.

** BMI -body mass index; BMI = weight $(\mathrm{kg}) /$ height $\left(\mathrm{m}^{2}\right)$.

\#control group vs. hypertension group, $\mathrm{p} \leq 0.05$.

$\Delta$ hypertension group vs. diabetes group, $\mathrm{p} \leq 0.05$. 
Table 3 Summary of demographic characteristics of neonates and Apgar scores (mean \pm standard deviation (min-max))

\begin{tabular}{|c|c|c|c|}
\hline Number of women $[\mathrm{N}=75]$ & Control group [ $n=31]$ & Hypertension group $[n=30]$ & Diabetes group [ $n=14]$ \\
\hline Length $[\mathrm{cm}]$ & $49.84 \pm 1.97(45-53)$ & $48.43 \pm 3.03(42-53)$ & $49.43 \pm 3.95(41-54)$ \\
\hline Weight [kg] & $3.49 \pm 0.51(2.27-4.54)$ & $3.12 \pm 0.88(1.73-4.65)$ & $3.54 \pm 0.75(1.83-4.50)$ \\
\hline BSA $\left[m^{2}\right]^{*}$ & $0.22 \pm 0.0 .02(0.10-0.17)$ & $0.21 \pm 0.04(0.13-0.14)$ & $0.23 \pm 0.03(0.13-0.14)$ \\
\hline Apgar score (1 min) & $8.97 \pm 1.36(5-10)$ & $7.9 \pm 1.33(5-10)$ & $8.79 \pm 1.26(6-10)$ \\
\hline Apgar score (5 min) & $9.58 \pm 0.83(7-10)$ & $8.83 \pm 0.90(7-10)$ & $9.43 \pm 0.82(7-10)$ \\
\hline Gestational age (weeks) & $39.6 \pm 0.8(39-42)$ & $37.9 .1 \pm 2.38(32-41) \#$ & $38.3 \pm 0.81(37-39) \# \#$ \\
\hline Neonatal gender (Male/Female) & $14 / 17$ & $22 / 8$ & $8 / 6$ \\
\hline
\end{tabular}

\#control group vs. hypertension group, $\mathrm{p} \leq 0.05$.

\#\#control group vs. diabetes group, $\mathrm{p} \leq 0.05$.

*Boyd 's equation BSA $=0.000327 *$ weight $(\mathrm{g})(0.7285-0.0188 \log 10$ weight $(\mathrm{g})){ }^{*}$ height $(\mathrm{cm})$.

in gestational age between groups in this study could not influence diazepam transfer [19].

\section{Pharmacokinetic analyses}

The concentrations of diazepam $(\mu \mathrm{g} / \mathrm{mL})$ in the maternal plasma $\left(\mathrm{c}_{\mathrm{m}}\right)$ and neonatal plasma at delivery (venous umbilical cord plasma $c_{v}$ and arteriala umbilical cord plasma $c_{a}$ ) are shown in Figure 1. The corresponding feto: maternal plasma concentration ratios $\left(\mathrm{c}_{\mathrm{v}} / \mathrm{c}_{\mathrm{m}}\right)$ and umbilical arterial: venous plasma ratios $\left(\mathrm{c}_{\mathrm{a}} / \mathrm{c}_{\mathrm{v}}\right)$ are shown in Table 1. In the control group fetal diazepam concentrations were higher than maternal diazepam concentrations in $71 \%$ of cases (feto: maternal ratios $>1$ ), while in hypertension group there were $80 \%$ of feto: maternal ratios higher than 1 and in diabetes group there were $78 \%$ feto: maternal ratios higher than 1 . Maternal diazepam concentrations were statistically higher in control $(0.09 \pm 0.06 \mu \mathrm{g} / \mathrm{mL})$ and hypertension group $(0.07 \pm$ $0.06 \mu \mathrm{g} / \mathrm{mL}$ ) compared to group of women with diabetes $(0.02 \pm 0.01 \mu \mathrm{g} / \mathrm{mL})$. Group of women with hypertension $(0.12 \pm 0.09 \mu \mathrm{g} / \mathrm{mL})$ and control group $(0.1 \pm 0.05 \mu \mathrm{g} / \mathrm{mL})$ had statistically higher arterial umbilical cord diazepam concentrations than group of women with diabetes $(0.04 \pm 0.03 \mu \mathrm{g} / \mathrm{mL})$. There was statistically lower diazepam umbilical venous concentration in diabetes group $(0.05 \pm 0.04 \mu \mathrm{g} / \mathrm{mL})$ compared to hypertension

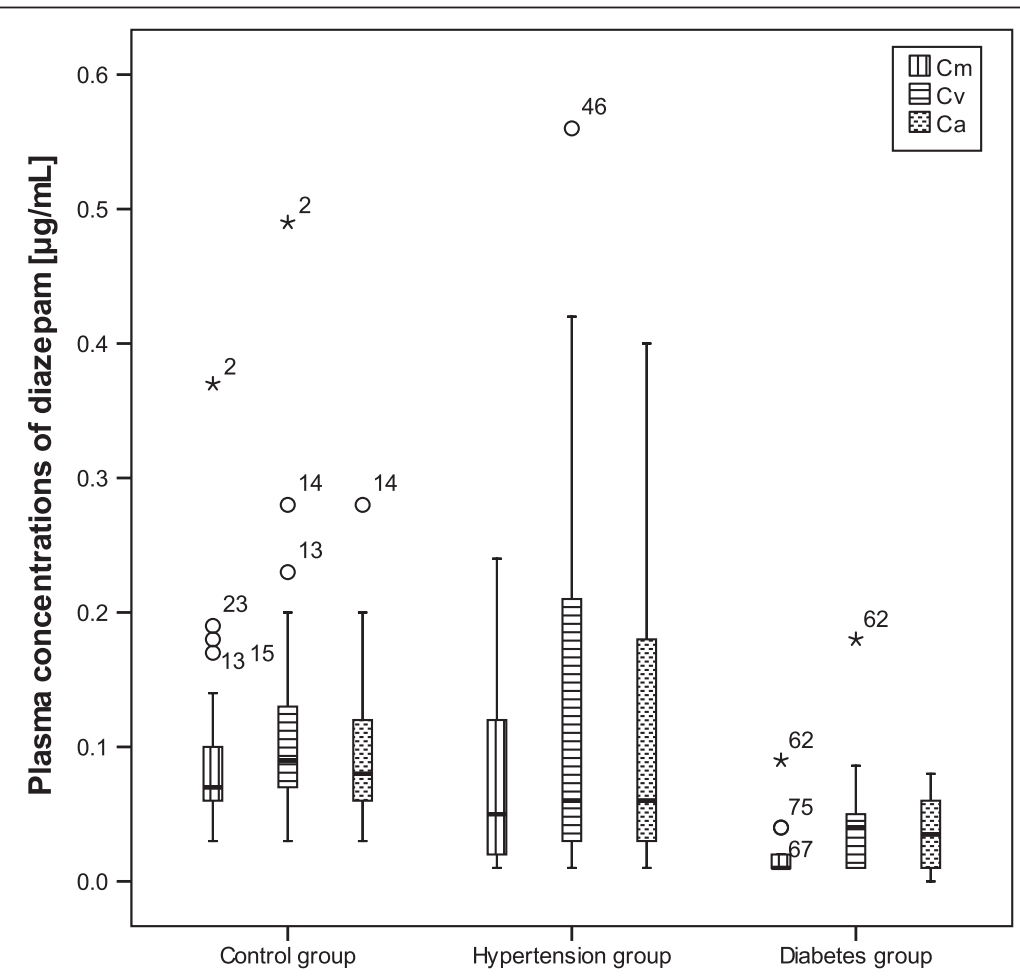

Figure 1 Box plots of diazepam concentrations $(\mu \mathrm{g} / \mathrm{mL})$ in maternal venous plasma $\left(C_{m}\right)$ and neonatal venous umbilical cord $\left(C_{v}\right)$ and arterial umbilical cord $\left(C_{a}\right)$ plasma at delivery [black stars represent extreme cases and white circles are outlier values]. 
group $(0.13 \pm 0.12 \mu \mathrm{g} / \mathrm{mL})$ and control group $(0.11 \pm$ $0.06 \mu \mathrm{g} / \mathrm{mL})$. In control group $45 \%$ of arterial: venous cord ratios were over 1 , while in diabetes and hypertension group $50 \%$ of arterial: venous cord ratios were over 1 , where in hypertension group 13\% and in diabetes group $7 \%$ of ratios were over 2 , which was not detected in control.

Study was approved under condition that it did not disturb the regular clinical procedures, which resulted in sampling times variability (Table 1). However, in this study diazepam was applied by long needle (21 gauges, $40 \mathrm{~mm}$ ) in the outer upper quadrant of the buttock by which it was avoided fat tissues thus it was expected to reach maximal concentrations after $0.30-1.30$ hours [20-22].

In Figure 2 are presented partial area under the curve values (AUC; $\min ^{*} \mu \mathrm{g} / \mathrm{mL}$ ) calculated from the zero time to the time at delivery (AUC $0-t_{2}$ ) and from the delivery time to the time of taken sample after cesarean section (AUC $t_{2}-t_{3}$ ). Values of AUC before delivery were taken as a measure of fetal exposure to diazepam. There were statistically higher AUC values before delivery in control and hypertension group compared to diabetes group. Values of AUC after delivery were statistically higher in control group compared to hypertension and diabetes group, but there were no significant differences between hypertension and diabetes group. Values of AUC after delivery were taken as a measure of diazepam elimination from the blood.

Diazepam concentrations in umbilical cord venous plasma, arterial cord plasma and maternal plasma were correlated with each other and weight, height, BSA, AUC and applied dose (Pearson's coefficient of correlation were calculated; $r^{2}$ ). Diazepam concentrations in umbilical cord venous plasma and concentrations in maternal venous plasma were positively correlated in all three groups $\left(r_{=}^{2} 0.75\right.$ control group; $r_{=}^{2} 0.80$ diabetes group and $r_{=}^{2} 0.77$ hypertension group, but in hypertension group three pairs were excluded from correlation). There were no correlations between dose, AUC, BSA, BMI, weight and maternal diazepam plasma concentrations at delivery $\left(C_{m}\right)$ or correlation between neonatal weight or BSA and umbilical cord plasma concentrations.

\section{Discussion}

Main finding of this study is that feto: maternal ratios were higher in hypertension and diabetes group compared to control group. Maternal diazepam concentrations were statistically higher in control and hypertension group compared to group of women with diabetes. Umbilical cord arterial: venous plasma concentration ratios were similar in all groups and they were not statistically different.

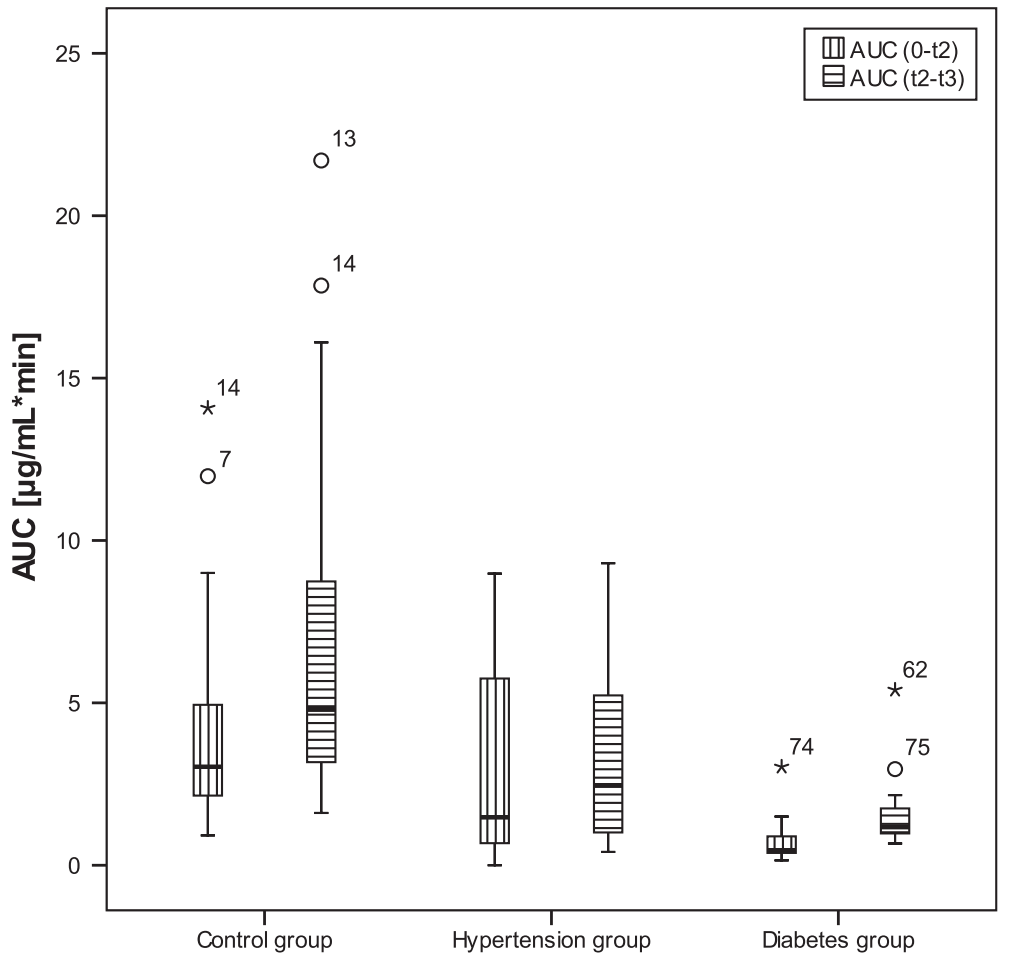

Figure 2 Box plots of partial AUCs of diazepam in maternal venous plasma from the zero time to the time at delivery (AUC 0 - $\left.t_{2}\right)$ and from the time of delivery to the time of taken sample after cesarean section (AUC $t_{2}-t_{3}$ ) [black stars represent extreme cases and white circles are outlier values]. 
The strength of this study is a prospective design which did not disturb regular clinical procedures. Limitation of this study is smaller number of pregnant women in diabetes group than in control and hypertension group.

In a majority of previous studies diazepam umbilical cord plasma concentrations exceeded maternal concentrations [23-25], although feto: maternal ratios below 1 have also been reported [26]. Diazepam is highly liposoluble and crosses placenta by passive diffusion via transcellular route $[27,28]$ thus diazepam transfer depends on properties of the placenta and is in a function of multiple factors such as placental blood flow, protein binding, lipid solubility and ionization constant (pKa).

In our study there were $76 \%$ of feto: maternal ratios above and $24 \%$ of feto-maternal ratios below 1 . There were also feto-maternal ratios above 2 (16\% control group; 57\% hypertension group; $36 \%$ diabetes group). This study demonstrates that feto: maternal ratios in diabetes and hypertension groups were significantly higher than in control. However, there was no difference between the ratios of the diabetes and hypertension groups. Since the administered doses of diazepam were similar in all groups, our findings show that there is a difference in diazepam transfer across placenta in the diabetes and hypertension groups.

There is no drug-drug interactions observed or reported [29-32] between diazepam and other administered drugs/anaesthetics, which indicates that diazepam absorption studies were not compromised.

Since no known interaction on pharmacokinetic level are expected between diazepam and insulin it was not considered that insulin treatment in 3 women in diabetes group had effect on concentration data.

Interestingly, in one study, a single oral dose of $5 \mathrm{mg}$ diazepam taken before dental treatment did not influence blood glucose level in nondiabetic and non-insulin dependent diabetic subjects [33]. But diazepam may alter insulin secretion and insulin sensitivity after a single administration in healthy volunteers [34], and diazepaminduced hyperglycemia, might be related to changes in serum chromium levels [35]. However in this study the increase in glycemia in diabetic women would be the result of the stress due to operation rather than diazepam treatment.

Binding of diazepam to human serum albumin can be influenced by hypertension and diabetes due to changes in hemodynamic properties or by drugs used for their treatment. Since diazepam is highly bound to proteins (96-99\%), and protein bound fraction of drug do not cross placenta [36], its metabolism rate and transplacental passage depends on free drug fraction. Diazepam is more protein bound in fetal circulation than in maternal circulation and it has one binding site on human serum albumin [37]. Since there is no known interactions at the level of protein binding between methyldopa or insulin nor drugs used in anaesthesia, observed higher feto: maternal ratios in diabetes and hypertension group could be consequence of the increased level of some endogenous substance in diabetes and hypertension, like free fatty acid which displace diazepam from proteins [38,39].

In the study by Ridd et al. [39] were found differences in protein binding of diazepam in maternal and diazepam plasma but free diazepam fractions were similar on both sides of placenta. Unbound drug concentrations in plasma are responsible for the obtained pharmacological effects, thus it would be expected that partial displacement of diazepam from plasma proteins would result in the increase in the magnitude of its pharmacological effects [40-43]. In our study there were no side effects in newborns (i.e. Apgar scores had normal values) or in mothers but this does not imply that there were no increase in diazepam free fraction. Since total clearance of diazepam is directly proportional to free diazepam fraction [44-46] and increased free diazepam fraction would lead to higher elimination and disappearance of diazepam from blood. This could be proved through AUC values after delivery which were statistically higher in control group compared to hypertension and diabetes group that implies that elimination of diazepam from central compartment is higher in hypertension and diabetes group and that is likely that there were more unbound diazepam in the blood in these groups.

Also other mechanisms such as metabolism and active transport could lead to differences in feto: maternal unit. Diazepam is metabolized by CYP enzymes some of which are present in placenta like CYP3A4 [47]. Presence of CYP 3A4 in human placenta is more than controversial, based on original and review articles [48], although some expression may be present at a very low, not functionally significant level. The most direct study on the absence of CYP3A-catalyzed metabolism was conducted on carbamazepine [49]. Previous studies showed that diazepam is not substrate for P-glycoprotein [50] but recent study suggested that diazepam is a modifier of P-glycoprotein because it behaved as an activator of the P-glycoprotein ATP-ase activity [51]. The potential of diazepam to modify P-glycoportein could affect placental transfer of other drugs which are substrates of P-glycoprotein. Still observed higher transplacental transition of diazepam in diabetes and hypertension group in our study may be due to lower activity of some other efflux proteins.

Ionic composition of cellular and extracellular space is altered in hypertension and diabetes due to altered work of some ion exchange pumps like $\mathrm{Na}^{+} / \mathrm{H}^{+}$and $\mathrm{Ca}^{2+} \mathrm{H}^{+}$ $[52,53]$. This could have influence on degree of diazepam ionization since if ionic strength of solution is lower 
dissociation balance shift to neutral molecules. Namely, diazepam is weak base (pKa 3.3), mainly unionized in blood ( $\mathrm{pH}$ 7.4) when unionized molecules leave plasma balance is shifted to new ionization. Since fetal plasma is slightly more acidic, 0.1 lower than maternal plasma $\mathrm{pH}$, the un-ionized free drug crossing the placenta becomes ionized and is 'trapped' in the more acidic fetal circulation $[54,55]$. In this study only in control group in all cases umbilical cord arterial: venous diazepam plasma concentration ratios were close to one, but in hypertension and diabetes group half of ratios were over one which means that higher maintenance of diazepam occurred within infants of mothers with diabetes or hypertension. As it was single dose use of diazepam and Apgar scores were not statistically different between groups there were no observed differences in pharmacological effect on neonates between groups. Some studies showed that maternal diazepam medication affects the beat-to-beat variability in the newborns [56] but duration of the effect is more profound in the chronic and infusion diazepam groups. However, it is known that diazepam free fraction increases shortly after birth which explains adverse effects observed clinically in some diazepam exposed neonates [57]. Thus it could be concluded that hypertensive and diabetic group neonates were in higher risk of serious diazepam side effects.

\section{Conclusions}

As expected, our findings show significant and direct effect of diabetes and hypertension development on diazepam absorption kinetics and transcellular trafficking across the placenta. On the other hand, the findings do not show a significant difference between diabetes and hypertension in diazepam placental-permeation. This raises further questions on the suitability of lipophilic drugs in pregnancy and future short and long term safety of the new born babies. Thus further studies are necessary to determine whether other lipophilic drugs also show such difference in placental-permeation.

\section{Competing interests}

The authors declared that they have no competing interests.

\section{Authors' contributions}

MLP carried out HPLC measurements and participated in analysis and interpretation of data, the design and writing of the manuscript. JP collected samples and participated in the design and writing of the manuscript. ZG supervised implementation of the study and participated in the design and writing of the manuscript. SGK and HAS participated in the design and writing of the manuscript. MM supervised the experiments, implementation of the study and participated in analysis and interpretation of data, the design and writing of the manuscript. All authors have seen and approved the final version.

\section{Acknowledgments}

This research was funded by Ministry of Science and Education of Serbia research project $\mathrm{N}^{0}$ III41012

\section{Author details}

'Department of Pharmacy, Faculty of Medicine, University of Novi Sad, Novi Sad, Serbia. ${ }^{2}$ Health department in Novi Sad for women health protection, Novi Sad, Serbia. ${ }^{3}$ Clinic of Gynecology and Obstetric, Clinical Centre of Vojvodina, Faculty of Medicine, University of Novi Sad, Novi Sad, Serbia. ${ }^{4}$ Faculty of Pharmacy, University of Montenegro, Podgorica, Montenegro. ${ }^{5}$ School of Pharmacy, Curtin Health Innovation Research Institute, Curtin University, Perth, WA, Australia. ${ }^{6}$ Faculty of Health Science, Central Queensland University, Queensland, Australia. 'Department of Pharmacology, Toxicology and Clinical Pharmacology, Faculty of Medicine, University Novi Sad, Novi Sad, Serbia.

Received: 17 May 2013 Accepted: 30 September 2013 Published: 17 October 2013

\section{References}

1. Al-Salami H, Butt G, Tucker I, Fawcett PJ, Golocorbin-Kon S, Mikov I, Mikov M: Gliclazide reduces MKC intestinal transport in healthy but not diabetic rats. Eur J Drug Metab Pharmacokinet 2009, 34:43-50.

2. Silver RM: Implications of the first cesarean: perinatal and future reproductive health and subsequent cesareans, placentation issues, uterine rupture risk, morbidity, and mortality. Semin Perinatol 2012, 36:315-323.

3. Watson WJ, George RJ, Welter S, Day D: High-risk obstetric patients. Maternal morbidity after cesareans. J Reprod Med 1997, 42:267-270.

4. LoCicero AK: Explaining excessive rates of cesareans and other childbirth interventions: contributions from contemporary theories of gender and psychosocial development. Soc Sci Med 1993, 37:1261-1269.

5. Mandelli M, Tognoni G, Garattini S: Clinical pharmacokinetics of diazepam. Clin Pharmacokinet 1978, 3:72-91.

6. Bakke $\mathrm{OM}$, Haram K: Time-course of transplacental passage of diazepam: Influence of injection-delivery interval on neonatal drug concentrations. Clin Pharmacokinet 1982, 7:353-362.

7. Combs CA, Gunderson E, Kitzmiller JL, Gavin LA, Main EK: Relationship of fetal macrosomia to maternal postprandial glucose control during pregnancy. Diabetes Care 1992, 15:1251-1257.

8. Mills JL: Malformations in infants of diabetic mothers. Teratology 1982, 25:385-394

9. Reece EA, Eriksson UJ: The pathogenesis of diabetes-associated congenital malformations. Obstet Gynecol Clin North Am 1996, 23:29-45.

10. Misra DP, Salafia CM, Miller RK, Charles AK: Non-linear and gender-specific relationships among placental growth measures and the fetoplacental weight ratio. Placenta 2009, 30:1052-1057.

11. Myatt $L$ : Role of placenta in preeclampsia. Endocrine 2002, 19:103-111.

12. Shafrir $E$, Khassis $\mathrm{S}$ : Maternal-fetal fat transport versus new fat synthesis in the pregnant diabetic rat. Diabetologia 1982, 22:111-117.

13. Thomas CR, Eriksson GL, Eriksson UJ: Effects of maternal diabetes on placental transfer of glucose in rats. Diabetes 1990, 39:276-282.

14. Many A, Schreiber L, Rosner S, Lessing JB, Eldor A, Kupferminc MJ: Pathologic features of the placenta in women with severe pregnancy complications and thrombophilia. Obstet Gynecol 2001, 98:1041-1044

15. Salafia CM, Pezzullo JC, Lopez-Zeno JA, Simmens S, Minior VK, Vintzileos AM: Placental pathologic features of preterm preeclampsia. Am J Obstet Gynecol 1995, 173:1097-1105

16. Ministry of Health of Republic Serbia: The good clinical practice national guidelines on diagnostic and treatment of arterial hypertension. In Book The Good Clinical Practice National Guidelines on Diagnostic and Treatment of Arterial Hypertension. Agency for the Accreditation of Health Care Institutions of Serbia; 2011:29-30.

17. Ministry of Health of Republic Serbia: The good clinical practice national guidelines on diabetes mellitus. In Book The Good Clinical Practice National Guidelines on Diabetes Mellitus. Agency for the Accreditation of Health Care Institutions of Serbia; 2012:69-71.

18. Rouini MR, Ardakani YH, Moghaddam KA, Solatani F: An improved HPLC method for rapid quantitation of diazepam and its major metabolites in human plasma. Talanta 2008, 75:671-676

19. Jauniaux E, Jurkovic D, Lees C, Campbell S, Gulbis B: In-vivo study of diazepam transfer across the first trimester human placenta. Hum Reprod 1996, 11:889-892. 
20. Dundee JW, Gamble JA, Assaf RA: Letter: plasma-diazepam levels following intramuscular injection by nurses and doctors. Lancet 1974 2:1461.

21. Gamble JA, Dundee JW, Assaf RA: Plasma diazepam levels after single dose oral and intramuscular administration. Anaesthesia 1975, 30:164-169.

22. Lamson MJ, Sitki-Green D, Wannarka GL, Mesa M, Andrews P, Pellock J: Pharmacokinetics of diazepam administered intramuscularly by autoinjector versus rectal gel in healthy subjects: a phase I, randomized, open-label, single-dose, crossover, single-centre study. Clin Drug Invest 2011, 31:585-597.

23. Kanto J, Erkkola R, Sellman R: Accumulation of diazepam and N-demethyldiazepam in the fetal blood during the labour. Ann Clin Res 1973, 5:375-379.

24. Kanto J, Scheinin M: Placental and blood-CSF transfer of orally administered diazepam in the same person. Pharmacol Toxicol 1987, 61:72-74.

25. McCarthy GT, O'Connell B, Robinson AE: Blood levels of diazepam in infants of two mothers given large doses of diazepam during labour. J Obstet Gynaecol Br Commonwealth 1973, 80:349-352.

26. Haram K, Bakke OM: Diazepam as an induction agent for caesarean section: a clinical and pharmacokinetic study of fetal drug exposure. Br J Obstet Gynaecol 1980, 87:506-512.

27. Dagenais C, Rousselle C, Pollack GM, Scherrmann JM: Development of an in situ mouse brain perfusion model and its application to mdr1a P-glycoprotein-deficient mice. J Cereb Blood Flow Metabol: Offic J Int Soc Cereb Blood Flow Metabol 2000, 20:381-386.

28. Park S, Sinko PJ: P-glycoprotein and mutlidrug resistance-associated proteins limit the brain uptake of saquinavir in mice. J Pharmacol Exp Therapeut 2005, 312:1249-1256.

29. Denson DD, Myers JA, Thompson GA, Coyle DE: The influence of diazepam on the serum protein binding of bupivacaine at normal and acidic $\mathrm{pH}$. Anesth Analg 1984, 63:980-984.

30. Feldman SA, Crawley BE: Interaction of diazepam with the musclerelaxant drugs. Br Med J 1970, 2:336-338.

31. Gerard JL, Edouard A, Berdeaux A, Duranteau J, Ahmad R: Interaction of intravenous diazepam and bupivacaine in conscious dogs. Reg Anesth 1989, 14:298-303.

32. Tomicheck RC, Rosow CE, Philbin DM, Moss J, Teplick RS, Schneider RC Diazepam-fentanyl interaction-hemodynamic and hormonal effects in coronary artery surgery. Anesth Analg 1983, 62:881-884.

33. Schaira VR, Ranali J, Saad MJ, de Oliveira PC, Ambrosano GM, Volpato MC: Influence of diazepam on blood glucose levels in nondiabetic and non-insulin-dependent diabetic subjects under dental treatment with local anesthesia. Anesth Progr 2004, 51:14-18.

34. Chevassus H, Mourand I, Molinier N, Lacarelle B, Brun JF, Petit P: Assessment of single-dose benzodiazepines on insulin secretion, insulin sensitivity and glucose effectiveness in healthy volunteers: a doubleblind, placebo-controlled, randomized cross-over trial [ISRCTN08745124]. BMC Clin Pharmacol 2004, 4:3.

35. al-Ahmed FA, el-Denshary ES, Zaki M, el-Sawaf HA, Abu-Jayyab AR: Interaction between diazepam and oral antidiabetic agents on serum glucose, insulin and chromium levels in rats. Biosci Rep 1989, 9:347-350.

36. Hill MD, Abramson FP: The significance of plasma protein binding on the fetal/maternal distribution of drugs at steady-state. Clin Pharmacokinet 1988, 14:156-170

37. Kober A, Sjoholm I, Borga O, Odar-Cederlof I: Protein binding of diazepam and digitoxin in uremic and normal serum. Biochem Pharmacol 1979, 28:1037-1042

38. Kuhnz W, Nau H: Differences in in vitro binding of diazepam and $\mathrm{N}$-desmethyldiazepam to maternal and fetal plasma proteins at birth: relation to free fatty acid concentration and other parameters. Clin Pharmacol Therapeut 1983, 34:220-226.

39. Ridd MJ, Brown KF, Nation RL, Collier CB: The disposition and placental transfer of diazepam in cesarean section. Clin Pharmacol Therapeut 1989, 45:506-512.

40. Benet $L Z$, Hoener BA: Changes in plasma protein binding have little clinical relevance. Clin Pharmacol Therapeut 2002, 71:115-121.

41. Berezhkovskiy LM: On the influence of protein binding on pharmacological activity of drugs. J Pharmaceut Sci 2010, 99:2153-2165.

42. Hammarlund-Udenaes M: Active-site concentrations of chemicals - are they a better predictor of effect than plasma/organ/tissue concentrations? Basic Clin Pharmacol Toxicol 2010, 106:215-220.
43. Schmidt S, Gonzalez D, Derendorf H: Significance of protein binding in pharmacokinetics and pharmacodynamics. J Pharmaceut Sci 2010, 99:1107-1122

44. Anderson GJ, Miller JW: Benzodiazepines: chemistry, biotransformation, and pharmacokinetics. In Antiepileptic Drugs. 5th edition. Edited by Levy RH, Mattson RH, Meldrum BS, Perrucca E. Philadelphia, PA: Lippincott Williams \& Wilkins; 2002:187-205.

45. Riss J, Cloyd J, Gates J, Collins S: Benzodiazepines in epilepsy: pharmacology and pharmacokinetics. Acta Neurol Scand 2008, 118:69-86

46. Shand DG, Kornhauser DM, Wilkinson GR: Effects of route of administration and blood flow on hepatic drug elimination. J Pharmacol Exp Therapeut 1975, 195:424-432.

47. Syme MR, Paxton JW, Keelan JA: Drug transfer and metabolism by the human placenta. Clin Pharmacokinet 2004, 43:487-514.

48. Hakkola J, Raunio H, Purkunen R, Pelkonen O, Saarikoski S, Cresteil T, Pasanen M: Detection of cytochrome P450 gene expression in human placenta in first trimester of pregnancy. Biochem Pharmacol 1996, 52:379-383.

49. Pienimaki P, Lampela E, Hakkola J, Arvela P, Raunio H, Vahakangas K: Pharmacokinetics of oxcarbazepine and carbamazepine in human placenta. Epilepsia 1997, 38:309-316.

50. Yamazaki M, Neway WE, Ohe T, Chen I, Rowe JF, Hochman JH, Chiba M, Lin $\mathrm{JH}:$ In vitro substrate identification studies for p-glycoprotein-mediated transport: species difference and predictability of in vivo results. J Pharmacol Exp Therapeut 2001, 296:723-735.

51. Lima SA, Tavares J, Gameiro P, de Castro B, Cordeiro-da-Silva A: Flurazepam inhibits the P-glycoprotein transport function: an insight to revert multidrug-resistance phenotype. Eur J Pharmacol 2008, 581:30-36.

52. Resnick LM, Gupta RK, Sosa RE, Corbett ML, Laragh JH: Intracellular pH in human and experimental hypertension. Proc Natl Acad Sci USA 1987, 84:7663-7667.

53. Smallwood Jl, Waisman DM, Lafreniere D, Rasmussen $\mathrm{H}$ : Evidence that the erythrocyte calcium pump catalyzes a $\mathrm{Ca} 2+\mathrm{nH}+$ exchange. J Biol Chem 1983, 258:11092-11097.

54. Holcberg G, Tsadkin-Tamir M, Sapir O, Huleihel M, Mazor M, Ben Zvi Z: New aspects in placental drug transfer. Israel Med Assoc J: IMAJ 2003, 5:873-876.

55. Matthew Dawes PJC: Pharmacokinetics in pregnancy. Best Pract Res Clin Obstet Gynaecol 2001, 15:819-826.

56. van Geijn HP, Jongsma HW, Doesburg WH, Lemmens WA, de Haan J, Eskes TK: The effect of diazepam administration during pregnancy or labor on the heart rate variability of the newborn infant. Eur J Obstet Gynecol Reprod Biol 1980, 10:187-201.

57. Nau H, Luck W, Kuhnz W: Decreased serum protein binding of diazepam and its major metabolite in the neonate during the first postnatal week relate to increased free fatty acid levels. Br J Clin Pharmacol 1984, 17:92-98.

doi:10.1186/1471-2393-13-188

Cite this article as: Lalic-Popovic et al:: Diabetes and hypertension increase the placental and transcellular permeation of the lipophilic drug diazepam in pregnant women. BMC Pregnancy and Childbirth 2013 13:188

\section{Submit your next manuscript to BioMed Central and take full advantage of:}

- Convenient online submission

- Thorough peer review

- No space constraints or color figure charges

- Immediate publication on acceptance

- Inclusion in PubMed, CAS, Scopus and Google Scholar

- Research which is freely available for redistribution 